\title{
Diffusion Bonding between Zr-Based Metallic Glass and Copper
}

\author{
Kou Hongchao, Guan Heng, Wang Jun, Tang Bin, Li Jinshan \\ State Key Laboratory of Solidification Processing, Northwestern Polytechnical University, Xi'an 710072, China
}

\begin{abstract}
The diffusion bonding capability between $\mathrm{Zr}_{41.25} \mathrm{Ti}_{13.75} \mathrm{Cu}_{12.5} \mathrm{Ni}_{10} \mathrm{Be}_{22.5}$ bulk metallic glass and pure $\mathrm{Cu}$ with and without interlayer was studied on a Gleeble3500 thermomechanical simulator. Experimental results show that good diffusion bonding joints without cracks and voids can be obtained under both conditions. Atomic diffusion at the interface is obviously observed using EDS and EPMA methods, while the diffusion zones are very narrow. The crystalline phases transformed from amorphous state will accelerate the atomic diffusion at the interface.
\end{abstract}

Key words: diffusion bonding; metallic glass; interlayer; interface

Bulk metallic glasses (BMGs) exhibit excellent mechanical, physical and chemical properties compared to traditional crystalline alloys as a result of their unique short-range order and long-range disorder microstructures ${ }^{[1-4]}$. Thus, they have a broad application prospects in the fields of electronics, machinery, chemicals and national defense. But the factors, such as room temperature brittleness and limited preparation dimension, have hindered their application as structural material ${ }^{[5]}$. In order to overcome the negative factors, multi-materials containing BMGs and crystalline alloys have been investigated recently. Many processing methods were adopted to join BMGs and crystalline alloys, such as explosive welding $^{[6,7]}$, electron beam welding ${ }^{[8,9]}$, pulse-current welding ${ }^{[10,11]}$, friction welding ${ }^{[10,12]}$ and friction stir welding method $^{[13,14]}$. However, the explosive welding is dangerous, electron beam welding and pulse-current welding will bring broad welding heat affected zone, and there exists lager residual stress at the interface during friction welding and friction stir welding. Compared with the previous welding means, the diffusion bonding method has the advantages of low bonding temperature, high bonding precision and small residual stress at the interface ${ }^{[15]}$. In the present paper, the diffusion bonding capability between $\mathrm{Zr}_{41.25} \mathrm{Ti}_{13.75} \mathrm{Cu}_{12.5} \mathrm{Ni}_{10} \mathrm{Be}_{22.5}$ (Vit1) BMG and pure $\mathrm{Cu}$ was studied on a Gleeble3500 thermomechanical simulator based on the thermoplastic property of the Zr-based BMG in its supercooled liquid region. The joining interface was characterized in detail using SEM, EDS and EPMA methods. The impact of adding Ni interlayer on the diffusion bonding between Vit1 and $\mathrm{Cu}$ was also studied.

\section{Experiment}

The ingots of master alloy with nominal composition of $\mathrm{Zr}_{41.25} \mathrm{Ti}_{13.75} \mathrm{Cu}_{12.5} \mathrm{Ni}_{10} \mathrm{Be}_{22.5}$ (at\%) were prepared by arc melting elements of $99.99 \mathrm{wt} \%$ purity metals in a water-cooled copper crucible under a high purity argon atmosphere $(\geq 99.999 \%)$. The ingots were remelted several times to ensure the compositional homogeneity. Cylindrical specimens with $9 \mathrm{~mm}$ in diameter and $25 \mathrm{~mm}$ in length were prepared by injection casting into a water-cooled copper mould under a high purity argon atmosphere. The amorphous structure of the specimen alloy was confirmed by X-ray diffraction. Then the amorphous specimen was turned into short cylinders with a dimension of $8 \mathrm{~mm}$ in diameter and $5 \mathrm{~mm}$ in length. As-drawn copper was selected and the dimension was also the same with the Zr-based metallic glass. The interlayer material was $\mathrm{Ni}$ foil with a thickness of $30 \mu \mathrm{m}$.

$\overline{\text { Received date: January 21, }} 2015$

Foundation item: Fundamental Research Fund of Northwestern Polytechnical University (JC20120203); Program of Introducing Talents of Discipline to Universities (B08040)

Corresponding author: Kou Hongchao, Ph. D., Associate Professor, State Key Laboratory of Solidification Processing, Northwestern Polytechnical University, Xi'an 710072, P. R. China, Tel: 0086-29-88460568, E-mail: hchkou@nwpu.edu.cn 
The Zr-based BMG and copper specimens were polished by $\mathrm{SiC}$ papers up to grit $2000 \#$, and then further polished to a mirror state using diamond polishing paste. In order to remove the surface hardening layer after polishing, the copper was cleaned with a $10 \%$ hydrochloric acid ethanol solution for $3 \mathrm{~min}$. All the specimens were ultrasonically cleaned in acetone for $5 \mathrm{~min}$ and then dried with cold wind before diffusion bonding test.

The glass transition temperature $\left(T_{\mathrm{g}}\right)$ and the first crystallization onset temperature $\left(T_{\mathrm{x}}\right)$ of $\mathrm{Zr}_{41.25} \mathrm{Ti}_{13.75} \mathrm{Cu}_{12.5} \mathrm{Ni}_{10} \mathrm{Be}_{22.5}$ measured by the differential scanning calorimeter (DSC, TA Instruments DSC2910, Al2O3 crucible) at a heating rate of 40 $\mathrm{K} / \mathrm{min}$ were 645 and $703 \mathrm{~K}$, respectively. The diffusion bonding temperatures adopted in the present paper were 663, 673 and $683 \mathrm{~K}$ under a press of $10 \mathrm{MPa}$ and the diffusion bonding time was 30 and $45 \mathrm{~min}$. In order to keep consistency with the DSC data, the heating rate in diffusion bonding test was still $40 \mathrm{~K} / \mathrm{min}$. The thermocouple was welded at the side of Vit1 near the interface. Vacuum during diffusion bonding was kept at $10^{-3} \mathrm{~Pa}$.

The diffusion bonding test was carried out on a Gleeble3500 thermomechanical simulator. The structures of the alloy as-cast and after joining were investigated by X-ray diffractometry (PHILIPS X' Pert MPD, $\mathrm{Cu} \mathrm{K} \alpha$ ). The joint quality was detected by scanning electron microscopy (SEM, TESCAN VEGAII LMH). The composition distribution along the interface was investigated by energy dispersive spectrometer (EDS, TESCAN VEGAII LMH) and electron probe micro-analyzer (EPMA, EPMA-1720).

\section{Results and Discussion}

Table 1 shows the parameters and results of diffusion bonding between Vit1 and $\mathrm{Cu}$. Under the condition without interlayer, the joint cannot be formed at a short time when the diffusion bonding temperature is $663 \mathrm{~K}$. When the bonding time reaches $45 \mathrm{~min}$, the joint can be formed. However, no joint is formed at low temperatures until the bonding temperature reaches $683 \mathrm{~K}$ under a pressure of $10 \mathrm{MPa}$ and holding for $45 \mathrm{~min}$ when a thickness of $30 \mu \mathrm{m} \mathrm{Ni}$ foil interlayer is added.

\subsection{X-ray diffraction analysis}

Fig.1 shows the XRD patterns of $\mathrm{Zr}_{41.25} \mathrm{Ti}_{13.75} \mathrm{Cu}_{12.5} \mathrm{Ni}_{10^{-}}$ $\mathrm{Be}_{22.5}$ bulk metallic glass of the as-cast and after diffusion bonding. The alloy still remains at amorphous state after heating for $45 \mathrm{~min}$ at the joining temperatures of 663 and $673 \mathrm{~K}$. While many crystalline diffraction peaks appear when the bonding temperature reaches $683 \mathrm{~K}$, indicating that crystalline phases have been generated from the substrate of amorphous alloy.

\subsection{Interface characteristics of $\mathrm{Vit1} / \mathrm{Cu}$ joint}

Fig.2 shows the backscattered electrons micrographs of the macrostructure and the microstructure of the joint in the diffusion bonding process with parameters of $663 \mathrm{~K}, 10 \mathrm{MPa}$ and $45 \mathrm{~min}$. The macroscopic plastic deformation occurs only at the side of $\mathrm{Zr}$-based metallic glass. As the bonding temperature
Table 1 Parameters and results of diffusion bonding between Vit1 and $\mathrm{Cu}$

\begin{tabular}{cccccc}
\hline \multirow{2}{*}{ Interlayer } & $\begin{array}{c}\text { Temperature/ } \\
\mathrm{K}\end{array}$ & $\begin{array}{c}\text { Pressure/ } \\
\mathrm{MPa}\end{array}$ & $\begin{array}{c}\text { Time/ } \\
\min \end{array}$ & $\begin{array}{c}\text { Deformation/ } \\
\%\end{array}$ & $\begin{array}{c}\text { Joints } \\
\text { forming }\end{array}$ \\
\hline \multirow{2}{*}{ No } & 663 & 10 & 30 & 14 & No \\
& 663 & 10 & 45 & 20 & Yes \\
\hline \multirow{3}{*}{$30 \mu \mathrm{m}$} & 663 & 10 & 45 & 20 & No \\
Ni foil & 673 & 10 & 45 & 23 & No \\
& 683 & 10 & 45 & 27 & Yes \\
\hline
\end{tabular}

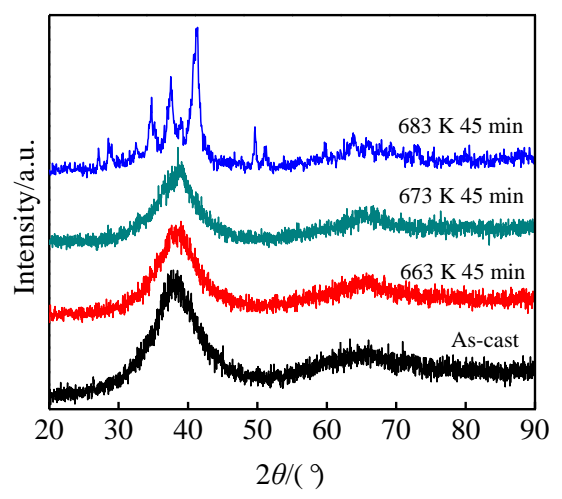

Fig.1 XRD patterns of $\mathrm{Zr}_{41.25} \mathrm{Ti}_{13.75} \mathrm{Cu}_{12.5} \mathrm{Ni}_{10} \mathrm{Be}_{22.5}$ bulk metallic glass of the as-cast and after diffusion bonding

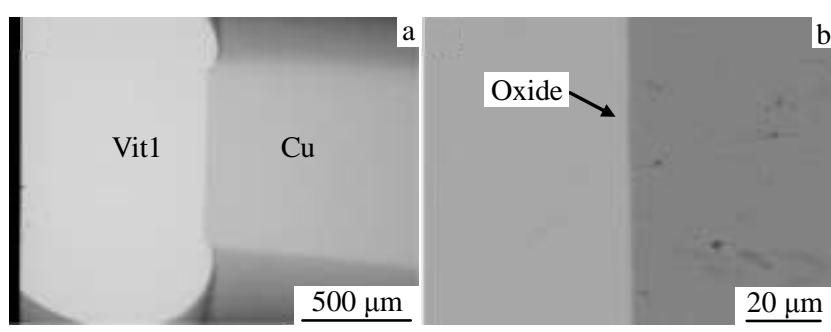

Fig.2 Backscattered electrons micrographs of the macrostructure (a) and microstructure (b) of the joint at the diffusion bonding process with parameters of $663 \mathrm{~K}, 10 \mathrm{MPa}$ and $45 \mathrm{~min}$

is within the super-cooled liquid region of amorphous alloy, the equilibrium viscosity of the alloy decreases sharply and the metallic glass exhibits superplasticity. The bonding pressure of $10 \mathrm{MPa}$ exceeds the flow stress at this temperature and therefore the alloy can be deformed easily. While for copper, the bonding pressure is lower than the flow stress so that macroscopic plastic deformation cannot occur. The interface between Vit1 and $\mathrm{Cu}$ is flat and no cracks and voids can be found as shown in Fig.2b. Chen has studied the contributions of atomic diffusion and plastic deformation to the diffusion bonding of $\mathrm{Zr}$-based metallic glass to crystalline aluminum alloy based on a mathematical model ${ }^{[15]}$. The study has found that plastic deformation plays a dominated role in the void shrinkage stage in the amorphous alloy side, while in the aluminum alloy side, atomic diffusion plays a major role. In the present paper, no obvious void can be found at the interface 
which indicates that the void has been completely eliminated by plastic deformation and atomic diffusion. But there is still some residual oxide film at the interface as shown with the arrow. Since copper is easily oxidized in air even after pickling treatment. Meanwhile the solubility of oxygen in copper is small and the oxide film at the interface tends to gather ${ }^{[16]}$. A part of the oxide film can be eliminated through the surface micro-plastic deformation. But when the oxide layer is thick, it cannot be eliminated completely during the diffusing bonding process. So a part of oxide film still exists at the interface.

In order to investigate the element diffusion at the interface, energy dispersive spectrometer analysis was adopted. Fig.3 shows the backscattered electrons micrograph and EDS curves of the joint interface under the diffusion bonding condition of $663 \mathrm{~K}, 10 \mathrm{MPa}$ and $45 \mathrm{~min}$.

From Fig.3 it can be seen that there is an obvious diffusion zone at the interface between Vit1 and Copper. The width of diffusion zone is less than $1 \mu \mathrm{m}$ combined with the EDS analysis. Meanwhile, the diffusion zone is in the copper side. The reason is that there are many diffusion channels in copper side, such as grain boundaries, crystallography defects and surface, which accelerate the atomic to diffuse from Vit1 side to copper side. However, due to the special close-packed structure of metallic glass, it is difficult for copper atoms to diffuse into the amorphous alloy. Because the atomic diffusion rate from Vit1 to copper is much faster than the opposite process, the obvious diffusion zone is in the copper side.

The detail of the element diffusion at the interface was further analyzed using the EPMA method, as shown in Fig.4. There is an obvious element diffusion zone at the interface and it is in the copper side. The result is well consistent with the EDS analysis. The result also indicates that atoms diffusion from Vit1 to copper is much easier than the opposite process. The width of the element diffusion zone is less than $1 \mu \mathrm{m}$ which is also consistent with the SEM result.

\subsection{Influence of $\mathrm{Ni}$ interlayer on the diffusion bonding between Vit1 and $\mathrm{Cu}$}

Since the thermal expansion coefficients between Vit1 and copper are quite different ${ }^{[17]}$, there exists a large residual stress at the interface when cooling from high temperature. So the

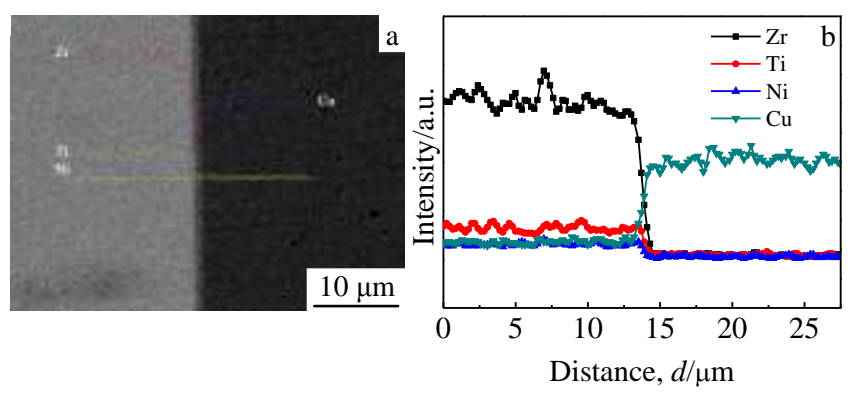

Fig.3 Backscattered electrons micrograph (a) and EDS analysis across the joint interface (b) under the diffusion bonding condition of $663 \mathrm{~K}, 10 \mathrm{MPa}$ and $45 \mathrm{~min}$

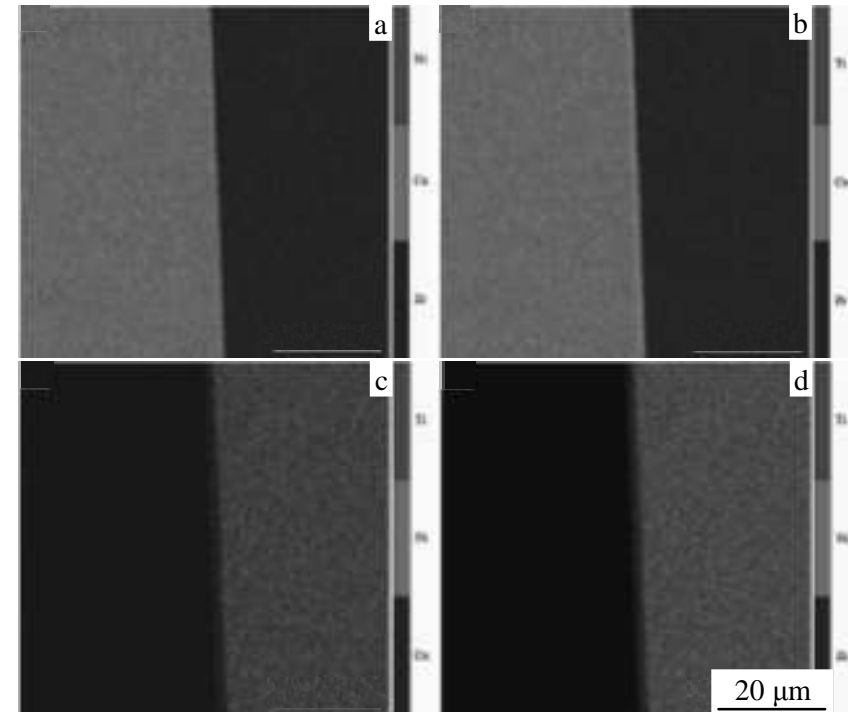

Fig.4 EPMA micrographs of joints at the interfaces: (a) elements of $\mathrm{Ni}, \mathrm{Cu}, \mathrm{Zr}$; (b) elements of $\mathrm{Ti}, \mathrm{Cu}, \mathrm{Zr}$; (c) elements of $\mathrm{Ti}, \mathrm{Ni}$, $\mathrm{Cu}$; (d) elements of $\mathrm{Ti}, \mathrm{Ni}, \mathrm{Zr}$

influence of Ni interlayer on the diffusion bonding between Vit1 and copper was investigated. $\mathrm{Ni}$ foil has good plasticity and ductility. The atomic radius of $\mathrm{Ni}$ is close to that of $\mathrm{Cu}$. Meanwhile, atoms can diffuse with the mechanism of miscible displacement among $\mathrm{Ni}$ and $\mathrm{Cu}^{[18]}$. On the other hand, the thermal expansion coefficient of $\mathrm{Ni}$ is lower than that of $\mathrm{Cu}$ and high than that of Vit $1^{[17,19]}$, which will relax the residual stress at the interface.

From Table 1 it can be found that no joint is formed at the diffusion bonding temperature of 663 and $673 \mathrm{~K}$ when $30 \mu \mathrm{m} \mathrm{Ni}$ interlayer is added. Because $\mathrm{Ni}$ foil was only cleaned with acetone before diffusion bonding process. The surface roughness is lager and a thick oxide layer exists at the surface of $\mathrm{Ni}$ foil. Many voids are formed at the early stage of diffusion bonding and the oxide layer baffles the diffusion process ${ }^{[16]}$. Meanwhile the metallic glass still remains at the amorphous stage. Voids and the oxide layer cannot be eliminated completely through plastic deformation and atomic diffusion process. However, when the bonding temperature reaches $683 \mathrm{~K}$, the joint is formed but the Zr-based metallic glass has transformed to crystal one. The emergence of crystalline phases promotes the atomic diffusion at the interface. Cao has found that argon ion irradiation changes the atomic structure of the surface layer of amorphous alloy ${ }^{[20]}$. A crystalline layer with a thickness of 20 30 $\mu \mathrm{m}$ occurs in the BMG side of the interface during the diffusion bonding process, and atomic diffusivity increases after crystallization which improves the quality of the joint. The same as the literature, in the present paper, since many crystalline phases are generated from the substrate of amorphous alloy which accelerates the atomic diffusion process, voids formed at the early stage are eliminated by the increased atomic diffusivity and plastic deformation. Fig.5 exhibits the backscattered 

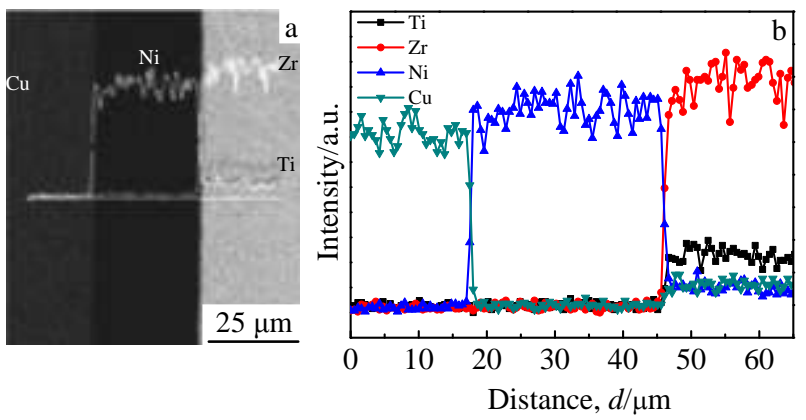

Fig.5 Backscattered electrons micrograph (a) and EDS curves at the interface (b) under the diffusion bonding condition of $683 \mathrm{~K}$, $10 \mathrm{MPa}$ and $45 \mathrm{~min}$

electrons micrographs and EDS curves of the interface under the diffusion bonding condition of $683 \mathrm{~K}, 10 \mathrm{MPa}$ and $45 \mathrm{~min}$. As seen from the SEM image, the interface looks continuous. No cracks and voids can be detected at the interface. This indicates that a well bonded interface has been formed with a $\mathrm{Ni}$ foil interlayer. The EDS curves show that atomic diffusion occurs at both interfaces of $\mathrm{Ni} / \mathrm{Cu}$ and $\mathrm{Ni} / \mathrm{Vit} 1$. But the atomic diffusion distance is very short.

\section{Conclusions}

1) Diffusion bonding joints between $\mathrm{Zr}_{41.25} \mathrm{Ti}_{13.75} \mathrm{Cu}_{12.5^{-}}$ $\mathrm{Ni}_{10} \mathrm{Be}_{22.5} \mathrm{BMG}$ and copper can be formed at the super-cooled liquid region temperatures based on the superplastic property of Zr-based BMG.

2) Atomic diffusion occurs at the interface and narrow diffusion zones are formed under both conditions with and without Ni foil.

3) Crystalline phases can be detected when the bonding temperature reaches $683 \mathrm{~K}$, which accelerates the atomic diffusion at the interface.

\section{References}

1 Inoue Akihisa, Zhang Wei, Zhang Tao et al. Journal of
Non-Crystalline Solids[J], 2002, 304: 200

2 Inoue Akihisa, Zhang Tao, Takeuchi Akira. Applied Physics Letters[J], 1997, 71: 464

3 Pang S J, Zhang T, Asami K et al. Acta Materialia[J], 2002, 50: 489

4 Lü J, Zhang J, Shek C. Rare Metal Materials and Engineering[J], 2013, 42(3): 447 (in Chinese)

5 Zhang Z F, Eckert J, Schultz L. Acta Materialia[J], 2003, 51: 1167

6 Liu W D, Liu K X, Chen Q Y et al. Applied Surface Science[J], 2009, 255: 9343

7 Friend C M, MacKenzie P J. Journal of Materials Science Letters[J], 1987, 6: 103

8 Kim J, Kawamura Y. Scripta Materialia[J], 2007, 56: 709

9 Kim J, Kawamura Y. Journal of Materials Processing Technology[J], 2008, 207: 112

10 Kawamura Y, Ohno Y. Materials Transactions(Japan)[J], 2001, 42: 717

11 Kawamura Y. Materials Science and Engineering: A[J], 2004, 375-377: 112

12 Wong C H, Shek C H. Scripta Materialia[J], 2003, 49: 393

13 Sun Yufeng, Ji Youngsu, Fujii Hidetoshi et al. Materials Science and Engineering $A[\mathrm{~J}], 2010,527: 3427$

14 Wang D, Xiao B L, Ma Z Y et al. Scripta Materialia[J], 2009, 60: 112

15 Chen H Y, Cao J, Liu J K et al. Computational Materials Science [J], 2013, 71: 179

16 Chen Zheng, Zhou Fei, Wang Guofan. Principle of Material Bonding[M]. Harbin: Harbin Institute of Technology Press, 2001: 202 (in Chinese)

17 Yu P, Liu Y, Wang G et al. Journal of Materials Research[J], 2007, 22: 2384

18 Liu Zhien. Fundamentals of Materials Science[M]. Xi'an: Northwestern Polytechnical University Press, 2007: 195 (in Chinese)

19 Nix F, MacNair D. Physical Review[J], 1941, 60: 597

20 Cao J, Chen H, Song X et al. Journal of Non-Crystalline Solids[J], 2013, 364: 53

\title{
$\mathbf{Z r}$ 基非晶合金与铜的扩散连接研究
}

\author{
寇宏超, 管 恒, 王 军, 唐 斌, 李金山
}

(西北工业大学 凝固技术国家重点实验室，陕西 西安 710072)

\begin{abstract}
摘 要: 利用Gleeble 3500 热模拟试验机在添加和未添加扩散连接中间层条件下对 $\mathrm{Zr}_{41.25} \mathrm{Ti}_{13.75} \mathrm{Cu}_{12.5} \mathrm{Ni}_{10} \mathrm{Be}_{22.5}$ 块体非晶合金与纯铜的扩散 连接性进行了研究。实验结果表明, 在 2 种条件下均获得了无裂纹和空洞的良好的连接界面。通过能谱分析和电子探针分析, 在连接界 面处观察到明显的原子扩散，但原子扩散距离较窄。非晶合金中晶化相的出现促进了界面处原子的扩散。
\end{abstract}

关键词：扩散连接；金属玻璃；中间层；界面

作者简介：寇宏超，男，1973 年生，博士，副教授，西北工业大学凝固技术国家重点实验室，陕西 西安 710072, 电话: 029-88460568, E-mail: hchkou@nwpu.edu.cn 